\title{
Impact of Educational Health Program on Quality of Life for Family Caregivers of Cancer Children Receiving Chemotherapy
}

\author{
Safaa A. Ali', Nelly A. Mahgoub², Somaya E. Aboabdou \\ Departments of ${ }^{1}$ Psychiatric and Mental Health Nursing, Faculty of Nursing, ${ }^{1}$ Fayoum University, ${ }^{2}$ Cairo University, \\ ${ }^{3}$ Suez Canal University
}

\begin{abstract}
Background: Cancer as a chronic illness affects the entire family life of the affected children and deteriorates their Quality of life (QoL). Objective: to contribute to improvement of quality of life of family caregivers of cancer children receiving chemotherapy. Subjects and Methods: The study was carried out at the Hematology and Oncology Unit in the pediatric department at Zagazig University Hospital, Sharkia governorate using a quasi experimental design on convenience sample of 78 family caregivers of children having cancer and on chemotherapy. Data collection tools included two tools namely an interview questionnaire form and scale for quality of life for family caregivers of medically ill patient. The researcher developed, implemented, and evaluated a health educational program for family caregivers. Results: The results revealed that the family caregivers have deficient knowledge about the disease and its treatment, associated with low QoL at pre program phase. The implementation of the program led to significant improvements in caregivers' knowledge. This significant improvement in knowledge has correlated significantly with improved QoL of family caregivers. Conclusion: the independent predictors of caregivers' QoL scores are the intervention score, means the intervention improving QoL. Dissemination of the educational program to other pediatric oncology hospitals, with involvement of other family members in the program is recommended.
\end{abstract}

Keywords: Mothers, Quality of life, Cancer Children

\section{Introduction}

Cancer in children is undoubtedly a life threatening illness, and a leading cause of mortality and morbidity. Sadly, this disease claims millions of children each year. However, it is a misconception to think that all forms of cancer are untreatable and deadly as there are multiple types of cancer in children, many of which can be effectively treated as remission detection may lead to more affordable and effective cancer treatment ${ }^{(1)}$. In Egypt, approximately 70,000 inpatient/outpatient visits to cancer hospitals are below 15 years old ${ }^{(2)}$. Childhood leukemia is the most common childhood cancer; with an annual incidence of $4.5: 100.000$ with percentage (37.7\%) followed by lymphomas $(12.5 \%)^{(3)}$. Child cancer and use of chemotherapy is a psychologically traumatic event enduring severe stress and burden for the family caregivers especially mother. Such stress is a result of not only the provision of the long-term as- 
sistance of housing and financial aid but also related to their roles in care giving for their children. Such burden is also a result of dealing with chemotherapy side effects and complications and the impact of child symptoms on family caregiver quality of life, other children, as well as interpersonal relationships within the family in addition to negative impact of stigma associated with cancer. Such stress and burden manifest itself in reduced family caregiver's QoL ${ }^{(4)}$. The psycho-oncology nurse should understand that different culture, behaviors, and religious beliefs that influence the illness experience; acknowledge that each child and family will deal with illness in their own way; approach the child and family in a calm manner; maintain eye contact during teaching; determine what they want to know before starting a discussion or teaching; listen to what is said; be receptive to nonverbal cues; respond to family caregivers feeling; and be sure if the family caregivers understand the information being presented $^{(5)}$. The aim of this study was to contribute to improvement of the quality of life of family caregivers having leukemic children receiving chemotherapy.

\section{Subjects and Methods}

The current study was conducted at pediatric cancer follow up day care unit at Hematology and Oncology department in Zagazig University hospital. A quasiexperimental design was used. The study population consisted of a convenience sample of 78 family caregivers who are regularly accompanying their children to the study setting during the period of the study. Data were collected using two tools to achieve the aim of the study.

Tool I: An interview questionnaire form was developed by the researcher and included two parts. Part l: for the Sociodemographic data of the caregivers and child, and a medical data sheet for the child. Part II: this part was intended to assess family Caregiver's knowledge before and after the intervention. It was designed by the researcher based on the literature review and supervisors' opinions. It tested caregiver's knowledge regarding cancer and chemotherapy. It consisted of eight open-end questions covering the nature of cancer, its types, malignancy, possible causes, treatment, value of chemotherapy, its side effects, and homecare.

Tool II: Brief Assessment Scale for Caregivers (BASC) of the Medically III: The scale was developed by Glajchen et $\mathrm{al}^{(6)}$ to assess the QOL of the family caregivers of seriously ill patients. It is composed of 14 items grouped into two subscales. The 4-items subscale rated on a 4-point Likert scale (not at all, a little, some, and a lot). The 8-item subscale for measuring negative personal impact rated on a 5-point Likert scale (not at all distressed, a little distress, some distress, and a lot of distress, does not apply). The tool has a good reliability (Cronbach's alpha 0.70). Its convergent validity was confirmed by inter-correlations with other measures of family caregiver QOL. The tool was translated into Arabic by the researcher to be applicable to Egyptians sample using the translate-re-translate method to ensure its validity ${ }^{(7)}$. Consent to conduct the study was taken from the hospital director, as well as from family caregivers themselves. The researcher contacted the mothers of cancer children receiving chemotherapy to explain the purpose and procedure of the study and determine the available time to demonstrate the educational program sessions. Mothers were interviewed individually to collect preassessment data related to sociodemographic, knowledge, and QoL. It lasted for 2 months. The researcher designed the program based on theoretical the conceptual framework of relevant and current litera- 
ture ${ }^{(8,9)}$, family caregivers' needs assessment. The content was divided into two sections; The first section (five sessions) provides family caregivers with knowledge related to cancer and its management, with particular emphasis on chemotherapy and its side effects, nutritional requirement for the child receiving chemotherapy, as well as the infection control and safety measures to enhance child's immunity. The second section (two sessions) focused on improving sleep pattern and QoL. Seven sessions distributed on 7 weeks, once weekly, each session lasted from 45 to 60 minutes. Each session had its own title and objective according to its content. The researcher designed an illustrative booklet in simple Arabic language to be distributed to participants containing all session of the educational program. One month after the end of the program, Mothers were interviewed to collect post-assessment data related to knowledge, and QoL.

\section{Results}

The age of children ranged between 2 and 12 years, with mean \pm SD $6.2 \pm 2.7$ years. Male children constituted approximately two-thirds of the sample (62.8\%), and only $29.5 \%$ were first in birth rank. The majority of the children were having siblings (84.6\%) (Table 1). The age of mothers ranged between 21 and 45 years while that of fathers ranged between 23 and 58 years. The highest percentage of mothers and fathers had intermediate education, $61.5 \%$ and $47.4 \%$ respectively. The majority of the mothers were housewives $(78.2 \%)$ and more than half of the fathers were manual workers (57.7\%). Only $10.3 \%$ of the children had divorced or widow parents (Table 2). Table (3) portrays that slightly more than half of family caregivers (56.4\%) had duration of care giving of twelve months or more, with a median 12 months. As for the spent time daily in care giving, approximately threefourth of the caregivers reported eight hours or more (73.1\%). As well, the majority of them (91.0\%) have supportive friends.

Table 1: Demographic characteristics of children in the study sample $(n=78)$

\begin{tabular}{|l|l|l|}
\hline Child characteristics & Frequency & $\%$ \\
\hline Gender: & \multicolumn{3}{|c|}{} \\
$\quad$ Male & 49 & 62.8 \\
Female & 29 & 37.2 \\
\hline Age (years): & \multicolumn{3}{|c|}{} \\
$\quad<6$ & 38 & 48.7 \\
$6+$ & 40 & 51.3 \\
Range & \multicolumn{3}{|c|}{$2.0-12.0$} \\
Mean \pm SD & \multicolumn{3}{|c|}{$6.2 \pm 2.7$} \\
Median & \multicolumn{3}{|c|}{6.00} \\
\hline Birth order: & 23 & 29.5 \\
1 & 55 & 70.5 \\
$2+$ & 12 & 15.4 \\
\hline Have siblings: & 66 & 84.6 \\
No & \multicolumn{3}{|c|}{} \\
yes &
\end{tabular}

Table (4) reveals that caregivers' preintervention knowledge was the lowest regarding the value of chemotherapy, while the highest was regarding the side effects of chemotherapy. The table points to statistically significant improvements in all the areas of knowledge at the postintervention stage of the study, reaching $100 \%$ in many of these areas. In total, 74 of the 78 participants had satisfactory knowledge at the post-intervention phase compared with 27 out of 78 in the pre-intervention phase, and this was statistically significant $(p<0.001)$. Only few of them had high level of QOL at the pre-intervention phase whether current (two caregivers) or previous month (three caregivers). However, the majority had high score of QOL during this month. At the post-intervention phase, statistically significant improvements were shown in caregivers' QOL currently $(p<0.001)$ and during the previous month $(p<0.001)$. In total, only 27 caregivers had high QOL before the intervention, 
and this increased to 76 after the intervention, with statistically significant difference ( $p<0.001$ ) (Table 5). The time remaining for chemotherapy was the only variable that had a statistically significant weak positive correlations with the score of knowledge $(r=0.196)$, and QOL $(r=0.178)$. QOL had a positive weak statistically significant correlation with caring hours $(r=0.302)$ and $a$ negative statistically significant correlation with the remaining time for chemotherapy $(r=-0.178)$ (Table 6).

Table 2: Socio-demographic characteristics of the studied family caregivers $(\mathrm{n}=78)$.

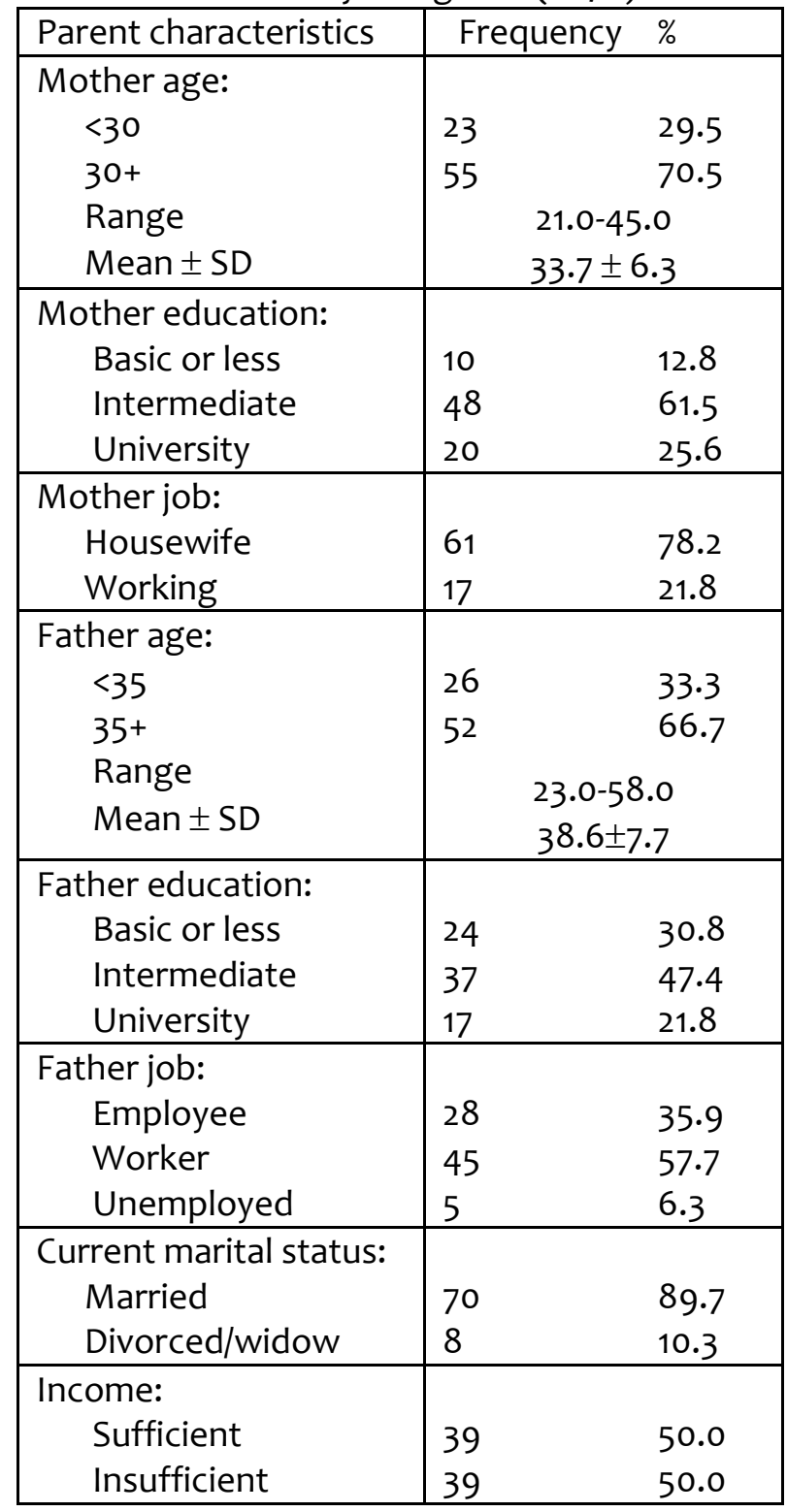

The best fitting multiple linear regression models for QOL scores is demonstrated in table (7). It shows that the statistically significant independent predictor of caregivers' QOL scores was the intervention (post program). It is noticed that the intervention was a negative predictor of QOL score, meaning improvement of QOL. The model explains $57 \%$ of the QOL score as shown by the value of $r$-square. Figure 1 illustrates statistically significant improvements in caregivers' knowledge, and quality of life at the post-intervention phase $(p<0.001)$.

\section{Discussion}

The findings of the current study indicated a higher percentage of boys among the children with cancer. This may be due to sex disparities in early diagnosis and treatment, which is common in the rural Egyptian families as they still value boys, so they may seek more medical care for them compared with girls. This finding agrees with other studies in Egypt ${ }^{(10-13)}$ as well as in other oriental countries as in $\operatorname{Iran}^{(14)}$, and in Pakistan where acute lymphoblastic leukemia occurs in boys about 1.5 times more commonly than girls ${ }^{(15)}$. Moreover, cancer was slightly more common in boys than in girls ${ }^{(16)}$. With regard to the age of children, the sample was equally divided at the age of 6 years. This indicated the absence of age predilection. Accordingly, the highest incidence rates of cancer generally occurs during the first five years of life and then show decreasing trends with age $\mathrm{e}^{(17)}$. However, some studies reported that cancer in children starts at age younger than 6 years ${ }^{(18,19)}$, while others reported more incidence among children aged 6 or more years $^{(20-22) .}$ Nonetheless, the type of cancer diagnosed can vary with age ${ }^{(16)}$. All the family members in the present study were mothers, mostly in the third decade of age, housewives, and having intermediate to high education. These characteristics make 
them most suitable for the process of care giving since they are young enough to have energy, educated enough to provide good care, and have enough time. In line with this ${ }^{(23)}$ found that caregivers who were in poor health or from low-income or dysfunctional situations might have the most limited capacity to provide needed care. They also might not understand the stand- ard for quality and might not provide the level of care that is needed. The highest percentage of mothers among caregivers is in congruence with ${ }^{(24)}$ who found that in studies of pediatric cancer up to $77 \%$ of mothers were the primary caregivers. Also, the age range is in line with that previously reported $^{(25)}$ In Iraq and in Jordan ${ }^{(26)}$.

Table 4: Family caregivers' knowledge of cancer and chemotherapy before and after the intervention

\begin{tabular}{|c|c|c|c|c|c|}
\hline \multirow{3}{*}{ Items } & \multicolumn{3}{|c|}{ Family caregivers' knowledge } & \multirow{3}{*}{$\begin{array}{c}\text { McNemar } \\
\text { test }\end{array}$} & \multirow[t]{3}{*}{$\mathrm{p}$-value } \\
\hline & \multirow{2}{*}{ pre } & po & & & \\
\hline & & Unsatisfactory & Satisfactory & & \\
\hline \multirow[t]{2}{*}{ Nature of cancer } & Unsatisfactory & 2 & 31 & \multirow[t]{2}{*}{29.032} & \multirow[t]{2}{*}{$<0.001^{*>}$} \\
\hline & Satisfactory & 0 & 45 & & \\
\hline \multirow[t]{2}{*}{ Types } & Unsatisfactory & 0 & 36 & \multirow[t]{2}{*}{34.028} & \multirow[t]{2}{*}{$<0.001 * *$} \\
\hline & Satisfactory & 0 & 42 & & \\
\hline \multirow[t]{2}{*}{ Malignancy } & Unsatisfactory & 0 & 33 & \multirow[t]{2}{*}{31.030} & \multirow[t]{2}{*}{$<0.001 * *$} \\
\hline & Satisfactory & 0 & 45 & & \\
\hline \multirow[t]{2}{*}{ Possible causes } & Unsatisfactory & 4 & 38 & \multirow[t]{2}{*}{36.026} & \multirow[t]{2}{*}{$<0.001 * *$} \\
\hline & Satisfactory & 0 & 36 & & \\
\hline \multirow[t]{2}{*}{ Treatment } & Unsatisfactory & 0 & 30 & \multirow[t]{2}{*}{28.033} & \multirow[t]{2}{*}{$<0.001 * *$} \\
\hline & Satisfactory & 0 & 48 & & \\
\hline \multirow[t]{2}{*}{ Value of chemotherapy } & Unsatisfactory & 1 & 49 & \multirow[t]{2}{*}{47.020} & \multirow[t]{2}{*}{$<0.001 * *$} \\
\hline & Satisfactory & 0 & 28 & & \\
\hline \multirow{2}{*}{$\begin{array}{l}\text { Chemotherapy Side } \\
\text { effects }\end{array}$} & Unsatisfactory & 0 & 23 & \multirow[t]{2}{*}{ Exact $P$} & \multirow[t]{2}{*}{$<0.001 * *$} \\
\hline & Satisfactory & 0 & 55 & & \\
\hline \multirow{3}{*}{ Home care } & Unsatisfactory & 0 & 25 & \multirow[t]{2}{*}{ Exact $P$} & \multirow[t]{2}{*}{$<0.001 * *$} \\
\hline & Satisfactory & 0 & 53 & & \\
\hline & Unsatisfactory & 4 & 47 & 45.021 & $<0.001 * *$ \\
\hline Total knowledge & Satisfactory & 0 & 27 & & \\
\hline
\end{tabular}

As the present study indicates, half of the family caregivers were having insufficient income. This may be a major source of dis tress, with guilt feelings for not being able to provide for the ill child. On the same line it was emphasized that the most important problem for families caring for children with cancer is the economic burden that the mother face ${ }^{(27)}$. The present study program was concerned with improving family caregivers' knowledge related to caring of their cancer children receiving chemotherapy. The pre-program assessment showed deficiency of their knowledge in many are- 
as such as value of chemotherapy and its side effects. The findings are alarming since the lack of knowledge may jeopardize the care-giving role. In this respect it was emphasized that despite good intentions and hard work, if caregivers do not have the knowledge and skills to perform their work; they may unintentionally harm their loved one ${ }^{(28)}$. This risk for injury is directly related to lack of knowledge and competence, which can be improved through caregiver education and support. Statistically significant improvements in family caregivers' knowledge at post-program phase indicates that they were in great need for information, and that the educational program was successful in achieving their needs. This might be attributed to the characteristics of the health education program, which was custom-tailored to real identified needs. In congruence with this, it has been emphasized that cancer caregivers require personalized educational materials that incorporate problem solving strategies, explanations of how to care for their relatives, and suggestions regarding how to maintain their own health. Such information should be presented in an easily understandable manner which encourages caregivers to seek assistance in needed areas $^{(29)}$. This success of the present study educational program is in agreement with similar previous studies in Egypt $^{(30)}$ and Saudi Arabia ${ }^{(31)}$. In the same vein ${ }^{(32)}$ in Brazil found that when the educational program was highly acceptable, it led to increased mothers confidence in their knowledge and practice, and to initiate discussion about emotional issues. Additionally, the booklet provided to caregivers in the present study helped in their acquisition and retention of knowledge, and might be an important reason underlying the success of the program. In agreement with this, it was reported that family caregivers needed to have enough clinically relevant information and evidence-based recommendations about the cancer, and chemotherapy ${ }^{(33)}$. They also reported that family caregivers expressed a need for various types of handouts distributed by the end of the program as this could have a positive impact on retention of information, helping them to know about ill children what they did not know.

Table 5: Caregivers' quality of life (QOL) before and after the intervention

\begin{tabular}{|c|c|c|c|c|c|}
\hline & & & & & \\
\hline & Pre & & & Micivemar & $\mathrm{p}$-value \\
\hline & & Low & High & & \\
\hline Current: & & & & & \\
\hline & Low (75\%) & 46 & 30 & & \\
\hline & High $(<75 \%)$ & 0 & 2 & 28.033 & $<0.001^{*}$ \\
\hline Previous month: & & & & & \\
\hline & Low (75\%) & 29 & 46 & & \\
\hline & High $(<75 \%)$ & 0 & 3 & 44.022 & $<0.001^{*}$ \\
\hline This month: & & & & & \\
\hline & Low (75\%) & 0 & 7 & & \\
\hline & High $(<75 \%)$ & 1 & 68 & Exact $p$ & 0.07 \\
\hline Total QOL & & & & & \\
\hline & Low (75\%) & 2 & 49 & & \\
\hline & High $(<75 \%)$ & 0 & 27 & 47.020 & $<0.001^{*}$ \\
\hline
\end{tabular}


Table 6: Correlation between caregivers' QOL, knowledge pre/post scores and the socio-demographic characteristics

\begin{tabular}{|l|cc|}
\hline \multirow{2}{*}{} & \multicolumn{2}{|c|}{ Spearman rank correlation } \\
\cline { 2 - 3 } & Knowledge & QOL \\
\hline Mother age & -0.041 & -0.018 \\
Father age & 0.002 & 0.016 \\
Father education & -0.034 & -0.036 \\
Income & 0.082 & 0.043 \\
Caring months & 0.078 & 0.007 \\
Caring hours & 0.018 & 0.085 \\
No. of friends & -0.128 & $.302^{* *}$ \\
Child age & 0.085 & -0.014 \\
Birth order & -0.071 & -0.038 \\
No. of siblings & 0.026 & -0.028 \\
Duration of illness & -0.059 & 0.002 \\
Remaining time & -0.077 & -0.011 \\
No. of side effects & $.196^{*}$ & $-.178^{*}$ \\
\hline
\end{tabular}

The present study aimed to improve the QOL of family caregivers. The study findings revealed a high prevalence of low QOL among these caregivers at the pre-program phase. This low QOL was significantly related to lower levels of parents' education, longer caring hours, and remaining time for chemotherapy. On the other hand, none of the child's socio-medical characteristics influenced caregiver's QOL. The findings imply that family caregivers' QOL was low irrespective of child's age, gender, birth order, or response to treatment. The finding might be explained by the seriousness and life-threatening nature of cancer, which overwhelms the effect of any other factors. However, the lower the caregiver's QOL is, the less is his/her ability to provide good care. In this respect, a prospective population-based cohort study found that caregiver's strain and low QOL increased mortality risk by $63 \%$ within 5 years ${ }^{(34)}$. In agreement with these foregoing present study findings, ${ }^{35}$ showed that the providers of care with lower levels of education attainment suffered significantly more distress than caregivers with higher education. They reported that care giving had a larger negative impact on their lives. A possible reason for this finding was that individuals with a higher level of education may have inquired about available resources and may have possessed the financial means to hire help when needed.

This would have decreased the amount of physical and psychological stress experienced by the caregiver leading to an overall better $\mathrm{QOL}^{(36)}$. Concerning the effect of the total number of hours per day spent in care giving and its inverse relation with the QOL of the present study caregivers, it might be explained by the fact that they are more burdened by their care giving tasks because of the longer hours spent with the care recipient. In agreement with this, the extended care giving hours may be viewed as a source of psychological distress and physical burden for caregivers ${ }^{(37)}$. It limits the amount of time that they are able devote to activities and responsibilities outside of care giving, and may be more physically demanding as the care recipients physical ability to care for themselves diminishes. All of these factors contribute to a decrease in the caregiver's QOL. 
Table 7: Best fitting multiple linear regression model for QOL scores

\begin{tabular}{|c|c|c|c|c|c|c|c|}
\hline & \multicolumn{2}{|c|}{$\begin{array}{l}\text { Unstandardized } \\
\text { Coefficients }\end{array}$} & \multirow[t]{2}{*}{$\begin{array}{l}\text { Standardized } \\
\text { Coefficients }\end{array}$} & \multirow[t]{2}{*}{ t-test } & \multirow[t]{2}{*}{$\mathrm{p}$-value } & \multicolumn{2}{|c|}{$\begin{array}{l}\text { Confidence } \\
\text { Interval (95\%) }\end{array}$} \\
\hline & B & SE & & & & Lower & Upper \\
\hline Constant & 84.249 & 4.384 & & 19.22 & $<0.001$ & 75.59 & 92.91 \\
\hline Intervention & -16.78 & 1.678 & -0.623 & 9.99 & $<0.001$ & -20.09 & -13.46 \\
\hline
\end{tabular}

r-square $=0.57$; Model ANOVA: $F=104.953, p<0.001$

The post-program phase of the current study revealed significant improvements in caregivers' QOL, with almost all of them having high QOL by the end of the intervention. This result is certainly attributed to the educational program, which provided these caregivers with needed knowledge, and coping skills that helped them undertake the daily care giving activities appropriately. This would subsequently have a positive impact on their QOL through improving their mental, physical and psychological conditions and promoting their own health and wellbeing.

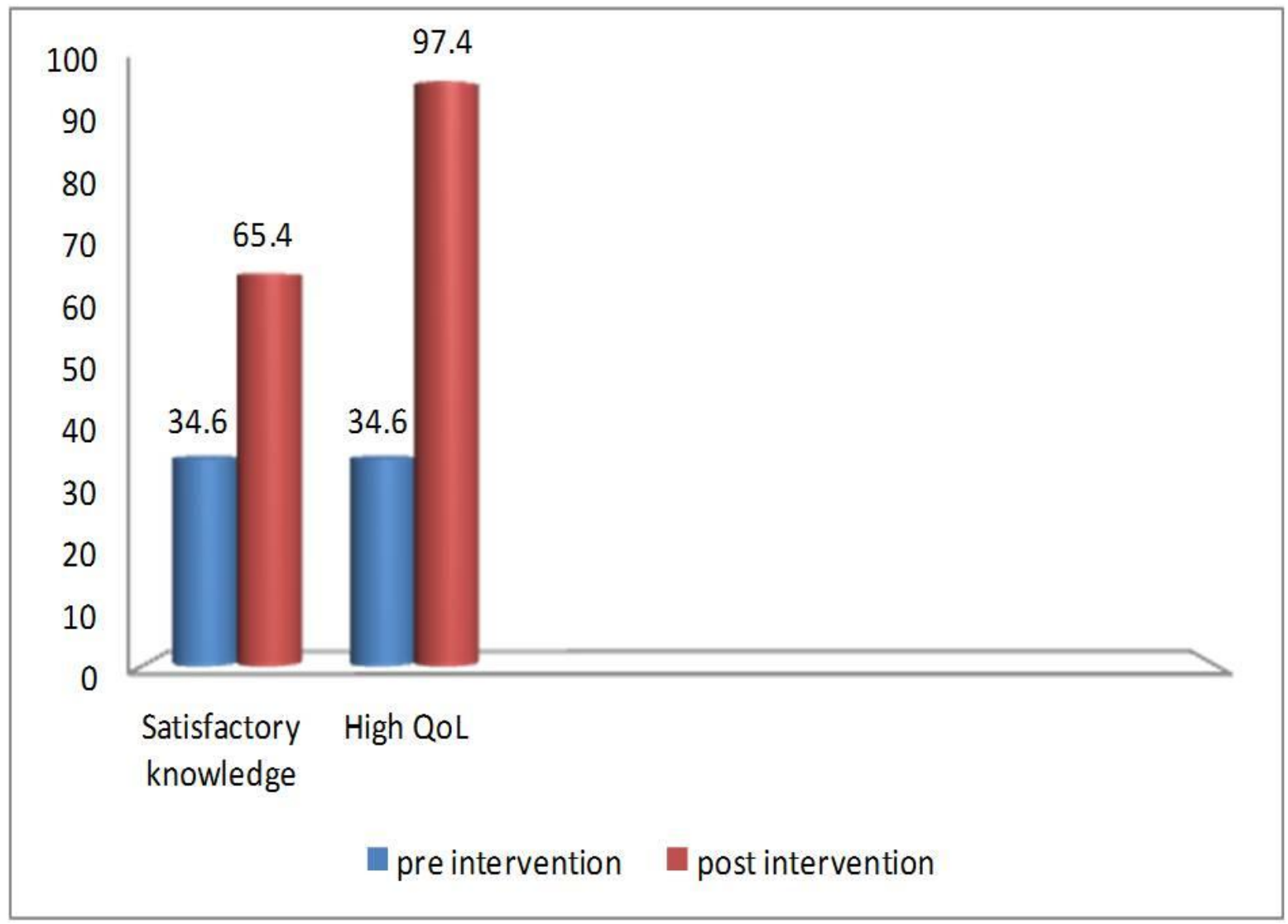

. Figure 1: Caregivers' knowledge and quality of life before and after the intervention

This has been confirmed by the results of the multivariate analysis, which identified that the intervention positively and independently predicted better QOL, while the depression score worsened it. Moreover, the correlation analysis demonstrated that knowledge improved QOL. These might be considered as the intermediate factors through which the intervention had its positive influence on caregivers' QOL. For instance, the knowledge gained concerning cancer, and the handling of different stressor facing family caregivers have enabled them to maintain control over their 
own environment and personal situations. These findings are in congruence with previous studies ${ }^{(38-41)}$. Furthermore, the present study family caregivers' knowledge was positively correlated with their QoL. This means that family caregivers with satisfactory knowledge scores easily had higher QOL. These results in line with similar studies in USA which reported that family caregivers with unsatisfactory knowledge scores easily experienced emotional distress and depression because of less flexibility in dealing with the ill child problems, which is indirectly reflected on child's health and other family members' interactions $^{(42,43)}$.

On the same line, health education was considered the most effective and important nursing role for improving the family caregivers' health as whole ${ }^{(44)}$. The health education that emphasize on improving coping strategies and resolve conflicting emotions, negative psychological reactions, and burden and emphasize on importance of support to family caregivers in all ways, social, emotional, and informational support, which indeed lead to improvement of their compromised QOL. Thus, knowledge is empowering; it can help family caregivers feel more in control and help them serve as advocates of their beloved child through the potentially complicated medical care system ${ }^{(45)}$. The improvement of caregivers' coping could also be a positive factor explaining the improvement in their QOL. This has been demonstrated by the correlation between the two variables scores, namely coping and QOL. This is quite plausible given the relief provided by various coping strategies. In congruence with this, it was mentioned that there is strong evidence to suggest that coping processes have significant relations to psychological symptoms, and consequently on the $\mathrm{QOL}^{(46)}$.
Finally, the success of the current study intervention could also be attributed to the organization of the sessions and the comfortable setting and schedule that suited the participants' circumstances. These elements have been shown to be crucial in such interventions to achieve their goals. In this context, Zarit and Femia $(2008)^{(47)}$ mentioned that intervention programs may not always be convenient for caregivers to attend due to logistic problems as times or distance to the caregiver. Moreover, when caregivers are able to receive assistance with their care-giving task and feel confident that they are making regarding their care recipient, they are more likely to have lowers levels of stress and burden, thus able to enjoy a better QOL.

\section{Conclusion}

The study concludes that the family caregivers of children having cancer showed deficient knowledge about the disease and its treatment, and low QoL. The implementation of the educational program led to significant improvements in caregivers' knowledge which correlated significantly with family caregivers' QOL. The study recommends i) Dissemination of this educational program to other pediatric oncology hospitals in Egypt. ii) Enhancing oncology nurses understanding of family caregivers needs for learning healthy coping strategies that can improve their quality of life.

\section{References}

1. Landier W, Bhatia S. Cancer survivorship: a pediatric perspective. Oncologist 2010; 13 (1):1181-1192.

2. World Health Organization (WHO). WHO cancer control program. 2012 Available at: http//www.WHO.Int. /medicenter/factsheet/fs29.

3. National Cancer Institute $[\mathrm{NCl}]$. Childhood Cancers 2012. Accessed in Aug 3, 
2013 at www.cancer.gov/cancer topics /types /childhood cancers.

4. Dunn MJ, Rodriguez EM, Barnwell AS, Grossenbacher JC, Vannatta K, Gerhardt CA, Compas BE. (2012). Posttraumatic stress symptoms in parents of children with cancer within six months of diagnosis. Health Psychology, 31, 176185.

5. Hockenberry MJ Wilson D Winkelstein $M L$ and Kline NE. Wong's Essentials of Pediatric Nursing. 7th ed. Mosby Comp. New Jercy, 2005; pp: 961- 969.

6. Glajchen M. Kornblith A. Homel P. Fraidin L. Mauskop A. Portenoy RK. Development of a brief assessment scale for caregivers of the medically ill. J Pain Symptom Manage 2005; 29(3): 245-254.

7. Behling O, Law K. Translating questionnaires and other research instruments: Problems and Solutions. Lewis-Beck MS, editor. Thousand Oaks: Sage, 2000; pp. 1-70.

8. Given B, Sherwood PR, Given CW. What knowledge and skills do caregivers need? Am J Nurs 2008; 108(9 Suppl.):28-34.

9. Ann B. Health -related quality of life, (Review of disease -Specific Quality of life Measurement Scales, library of Congress Cataloging -in Publication Data 2001, Philadelphia, British.

10. Hussein M.H. Acute lymphoblastic leukemia in children, 16 th congress of the International Society of Hematology. European-African Division, Cairo, Egypt. in cancer care. J Support Oncol 2002; (2): 145-55.

11. Hassan T.H. P-Glycoprotein Expression Level and its Significance in Induction of Remission in Childhood Acute Leukemia 2005; Master Thesis, Faculty of Medicine, Zagazig University.

12. Bisheer M.R. Apoptosis Modulators: BCL-2 and P53 Proteins in Childhood Acute Lymphoblastic Leukemia 2006; Master Thesis, Faculty of Medicine, Zagazig University.

13. El-Kady WM. Psychological problems among leukemic school children and their parents. Master theses in psychi- atric and mental health nursing 2011; Faculty of nursing, Ain Shams University.

14. Hashemi F, Razavi SH, Sharif F, Shahriari MM. Coping strategies used by parents of children with cancer in Shiraz, Southern Iran. IRCMJ 2007; 9(3):124128.

15. Fadoo Z. Ashraf SH. Naqvi A. Imam U. Hamid S. Raza M. Nisar I. and Belguami A. Induction outcomes in children with acute lymphoblastic leukemia: Children Cancer Hospital, 2012; Karachi, Pakistan.

16. Canadian Cancer Society. Canadian Cancer Statistics 2008; at www.cancer. ca/Canadawide/About\%20cancer/Cancer\%20st atistics/Canadian\%20Cancer\%20 Statistics. aspx?sc.lang=en

17. Canadian Cancer Society. Canadian Cancer Statistics; 2011. At www.cancer .ca/ /media/CCS/Canada\% 20 wide/Files $\% 20$ List/English\%20 files\%20 heading /PDF\%20-\%20 Policy \%20-20 Canadian\%20Cancer \%20 Statistics\%20-\%20English /Canadian\% 20 Cancer\%20 Statistics\% 202011\%20-\%20 English.ashx.

18. El-Sabely A.A. Impact of maternal educational program on the care of their leukemic children 2008; Submitted in Partial Fulfillment of the Requirement for the Doctorate Degree in Pediatric Nursing. Faculty of nursing Zagazig University, p. 114-117.

19. Pui $\mathrm{CH}$, Relling MV, Downing JR. Acute Lymphoblastic Leukemia. N Engl J Med 2004; 350(15):1535-1548. at http:// content.nejm.org/cgi/content/extract/350/ 15/1535.

20. Farouk S.M. Ibrahim L.Y. Essa1 E.A. Fahim F.A. and Abdalla N.A. Biochemical study on normal and leukemic Egyptian children. Egypt J. Med. Lab. Sci., Sep. 2007; 16(2):89-97

21. Mousavi SM, Pourfeizi A, Dastgiri S. Childhood Cancer in Iran. J Pediatr Hematol Oncol 2010; 32(5): 376-382.

22. Van-Heerden J, Desai F, Hendricks $M$, Mathiassen W, Shuttleworth M, Davidson $A$. Race as a prognostic determinant in children with acute Lymphoblastic leukemia (all) 2012; A review of 
the Red Cross children's hospital experience 1995-2007.

23. Fulmer T, Paveza G, VandeWeerd C, Fairchild S, Guadagno L, Bolton-Blatt $M$, Norman R. Dyadic vulnerability and risk profiling for elder neglect. Gerontologist 2005; 45 (4):525-534.

24. Bonner MJ, Hardy $K K$, Guill $A B$, McLaughlin $\mathrm{C}$, Schweitzer $\mathrm{H}$, Carter $\mathrm{K}$. Development and validation of the parent experience of child illness. J Pediatr Psychol 2006; 31(3): 310-321.

25. Iqbal A, Siddiqui KS. Depression among parents of children with acute lymphoblastic leukemia, Shaukat Khanum Memorial Cancer Hospital and Research Centre 2010, Pakistan: Lahore, 2010 pp $1-4$.

26. Al-Jauissy MS. Health care needs of Jordanian caregivers of patients with cancer receiving chemotherapy on an outpatient basis East Mediterr Health J 2010;16 (10):1091- 1097.

27. Eiser C, Upton P. Costs of caring for a child with cancer: a questionnaire survey. Child Care Health Dev. 2007; 33(4): 455-459.

28. Silver HJ, Wellman NS, Arnold DJ, Livingstone AS, Byers PM. Older adults receiving home eternal nutrition: Enteral regimen, provider involvement, and health care outcomes. JPEN J Parenter Enteral Nutr 2004; 28(2):92-98.

29. O'Mara A. Who's taking care of the caregiver? J Clin Oncol. 2005; 23(28): 6820-6821.

30. Elsayed ME, Mahmoud SHF. Outcome of Enhancement of Maternal knowledge and Practice on health status of their children with cancer. Journal of American Science 2012; 8(3):322-333.

31. Draz FS, Bayoumi RO, El- Nagger SN. Respiratory Problems of Children with Cerebral palsy: Effect of Educational Program for their Mothers' Performance. J Am Sci 2013; 9(7):1-12.

32. Beltrao MR, Vasconcelos MG, Pontes $C M$, Albuquerque MC. Childhood cancer: maternal perceptions and strategies for coping with diagnosis in a pedi- atric unit in Brazil. J Pediatr 2007; 83 (6): 52-54.

33. Shabanzadeh V. "Cancer Knowledge, Problem Solving Ability, and Psychological Adjustment in Mothers of Newly Diagnosed Pediatric Cancer Patients," in California School of Professional Psychology 2001. vol. 3. Doctor of Philosophy in Psychology Los Angeles: California School of Professional Psychology.

34. Kim Y, Given BA. Quality of life of family caregivers of cancer survivors: across the trajectory of the illness. Cancer 2008; 112 (11 Suppl): 2556-2568.

35. Iconomou G, Viha A, Kalofonos HP, Kardamakis D. Impact of cancer on primary caregivers of patients receiving radiation therapy. Acta Oncol. 2008; 40(6):766-771.

36. Francis LE. The effectiveness of quality of life studies on understanding informal cancer caregiver stress, strain and burden. A Research Project Report Submitted in Partial Fulfillment of the Requirements for the Degree of Master of Science in Medical Dosimetry, College of Science \& Health, Medical Dosimetry Program 2012.

37. Yabroff KR, Kim Y. Time costs associated with informal caregiving for cancer survivors. Cancer. 2009; 115(S18):43624373.

38. Othman A. Hussin A. Mohamad N. and Azhar Z. Factors Related to Parental Well Being in Children with Cancer. 2011; International Conference on Social Science and Humanity IPEDR vol.5. IACSIT Press, Department of Pediatric University Sains Malaysia Kelantan, Malaysia.

39. Santo E, Gaíva M, Espinosa M, Barbosa D, Belasco A. Taking Care of Children with Cancer: Evaluation of the Caregivers' Burden and Quality of Life. Rev Latino-Am. Enfermagem. 2011; 19(3):515522

40. Poley MJ, Brouwer WB, van Exel NJ, Tibboel D. Assessing health-related quality-of-life changes in informal caregivers: an evaluation in parents of children with major congenital anomalies. Qual Life Res 2012; 21:849-861. 
41. Given BA, Given CW, Sherwood PR. Family and Caregiver Needs over the Course of the Cancer Trajectory. J Support Oncol. 2012;10(2): 57-64.

42. Zauszniewski JA, Bekhet AK, Suresky MJ. Factors associated with perceived burden, resourcefulness, and quality of life in female family members of those with mental illness. J Am Psychiatr Nurses Assoc. 2008; 14 (2): 123-125.

43. Musil C, Warner C, Zauszniewski J, Wykle M, Standing T. Grandmother caregiving, family stress and strain, and depressive symptoms. West J Nurs Res . 2009; 31 (3): 389-408.
44. Rahimirad H. Parental Attitudes and the Conflicts inside Families; (Value from the social aspect). Life Science Journal. 2013; 10(4s): 463

45. Hudson PL, Remedios C, Thomas K. A systematic review of psychosocial interventions for family caregivers of palliative care patients. BMC Palliat Care. 2010; 9:17.

46. Folkman S. The case for positive emotions in the stress process. Anxiety, Stress Coping. 2008; 21 (1): 3-14.

47. Zarit S, Femia E. Behavioral and psychological interventions for family caregivers. Am J Nurs. 2008; 108(9 suppl):4753. 